Provided for non-commercial research and education use. Not for reproduction, distribution or commercial use.

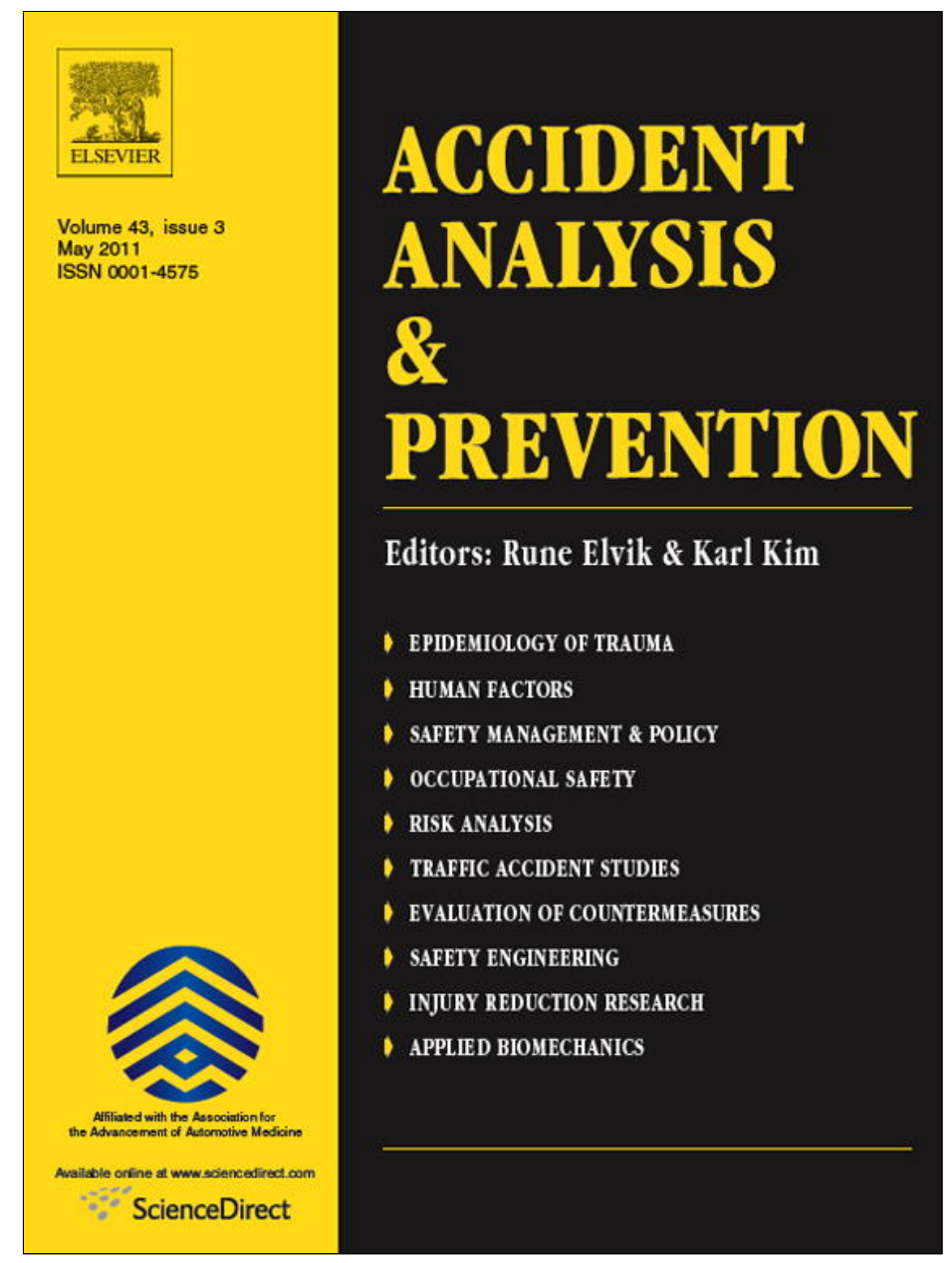

This article appeared in a journal published by Elsevier. The attached copy is furnished to the author for internal non-commercial research and education use, including for instruction at the authors institution and sharing with colleagues.

Other uses, including reproduction and distribution, or selling or licensing copies, or posting to personal, institutional or third party websites are prohibited.

In most cases authors are permitted to post their version of the article (e.g. in Word or Tex form) to their personal website or institutional repository. Authors requiring further information regarding Elsevier's archiving and manuscript policies are encouraged to visit:

http://www.elsevier.com/copyright 


\title{
Determining the drivers' acceptance of EFTCD in highway work zones
}

\author{
Yong Bai ${ }^{\mathrm{a}, *}$, Yingfeng $\mathrm{Li}^{\mathrm{b}, 1}$ \\ a Department of Civil, Environmental and Architectural Engineering, The University of Kansas, Lawrence, KS 66045, USA \\ ${ }^{\mathrm{b}}$ Texas Transportation Institute, Texas AE'M University System, San Antonio, TX 78229, USA
}

\section{A R T I C L E I N F O}

\section{Article history:}

Received 16 July 2009

Received in revised form 24 October 2010

Accepted 25 October 2010

\section{Keywords:}

Highway

Work zone

Crash

Traffic control devices

Safety

Survey

\begin{abstract}
A B S T R A C T
Traffic safety is a major concern in the temporary one-lane, two-way highway work zones due to the increasing of construction and maintenance operations. To prevent rear-end crashes and to mitigate the severity of these crashes caused by the inattentive driving, the utilization of the Emergency Flasher Traffic Control Device (EFTCD) was under consideration by government agencies, in addition to existing temporary traffic control devices installed in the one-lane, two-way highway work zones. The EFTCD was a newly proposed traffic warning device implemented through the use of vehicles' hazard warning flashers. The primary objective of the research project was to investigate the drivers' acceptance of the proposed EFTCD by measuring the mean speed changes of vehicles with and without EFTCD and by evaluating the drivers' opinions of the EFTCD using the survey method. Field experimental results revealed that the EFTCD effectively reduced the mean vehicle speeds in the upstream of two work zones. A slow speed is more likely to reduce the severity of a crash in work zones. In addition, survey results indicated that $60 \%$ of the drivers thought the EFTCD signified a need for speed reduction and $82 \%$ of drivers recommended the implementation of the EFTCD in one-lane, two-way work zones. These results provide the necessary scientific justifications for the government agencies to decide if the EFTCD should be implemented in the one-lane, two-way highway work zones to prevent rear-end crashes and to mitigate the severity of these crashes.
\end{abstract}

(c) 2010 Elsevier Ltd. All rights reserved.

\section{Introduction}

Two-lane highways constitute a large percentage of the highway system in the United States. Preserving, rehabilitating, expanding, and enhancing these highways require the temporary set up of a large number of one-lane, two-way work zones. It has become a critical challenge for traffic engineers to maintain a satisfactory level of safety in these work zones without sacrificing highway functions. For highway work zone related vehicle crashes in the State of Kansas, $61 \%$ of fatal crashes and 33\% of injury crashes took place in one-lane, two-way work zones from 1992 to 2004 (Bai and $\mathrm{Li}, 2006,2007)$. During the same period, 157 fatal crashes and 4443 injury crashes were observed in Kansas work zones. Majority of the work zone related vehicle crashes in Kansas were associated with human errors. Among the human errors, inattentive driving and speeding were the most common contributing factors which were responsible for $53 \%$ and $25 \%$ of the total fatal crashes, respectively, and $51 \%$ and $16 \%$ of the total injury crashed, respectively, from 1992 to 2004 (Bai and Li, 2006, 2007). Currently, the temporary traffic

\footnotetext{
* Corresponding author. Tel.: +1 785864 2991; fax: +1 7858645631.

E-mail addresses: ybai@ku.edu (Y. Bai), y-li@tamu.edu (Y. Li).

1 Tel.: +1 210731 9938x34; fax: +1 2107318904 .
}

control (TTC) devices required by the Manual on Uniform Traffic Control Devices (MUTCD) are installed in each work zone. However, utilizing these devices alone cannot prevent vehicle crashes from happening. One-lane, two-way work zones are typically set up for relatively short durations and required frequent movement during construction or maintenance operations. Thus, there is an urgent need to develop an effective TTC device that is highly visible, low cost, and easily assemble and removable for the one-lane, two-way work zones.

Aimed at reducing rear-end crashes attributable to inattentive driving in one-lane, two-way work zones, government agencies were considering the utilization of a newly proposed traffic control device, called the Emergency Flasher Traffic Control Device (EFTCD), which was assembled using the emergency warning flashers of vehicles. The proposed EFTCD would be implemented by requiring drivers to turn on their emergency flashers when stopped at the entrance of a one-lane, two-way work zone with the flagger and pilot car operation in order to signal following vehicles of the upcoming work zone traffic conditions. Ideally, the drivers of all vehicles would consecutively illuminate their flashers until all of them safely reach the end of the work zone. Thus, drivers would receive additional warning of the traffic conditions from preceding vehicles, apart from the TTC devices already present in the work zones. Before fully implementing the EFTCD in the one-lane, 
two-way work zones, there was a need to determine the drivers' acceptance of this newly proposed traffic control device.

\section{Objective and methodology}

The primary objective of the research project was to investigate the drivers' acceptance of the proposed EFTCD by measuring vehicle mean speed changes with and without EFTCD and by evaluating the drivers' opinions of the EFTCD using the survey method. In this research project, a without EFTCD work zone means that a site has only TTC devices required by the MUTCD; and a with EFTCD work zone means that a site has both TTC devices required by the MUTCD and the newly proposed EFTCD. The investigation was conducted using a five-step approach. First, authors conducted a comprehensive literature review and synthesized findings from previous studies relating to work zone traffic control methods and effectiveness. Second, authors designed field experiments to compare changes in vehicle mean speeds with and without the EFTCD in the upstream of one-lane, two-way highway work zones. Third, the collected speed data were analyzed using the statistical methods such as the ANOVA test and two-sample $t$-test. Fourth, five survey questions with multiple-choice answers were developed to assess the drivers' opinions of the EFTCD. Finally, authors concluded the drivers' acceptance of the EFTCD based on the outcomes of experimental and survey data analyses. Recommendations for the future research needs were also outlined.

\section{Literature review}

A comprehensive literature review was conducted to evaluate the effectiveness of current traffic control measures in highway work zones. Highway work zones use TTC devices to ensure reasonably safe and efficient traffic flow during road construction and maintenance. TTC devices that are commonly used in work zones include flaggers, traffic signs, channelizing devices, portable changeable message signs, lighting devices, temporary traffic control signals, pavement markings, and rumble strips (FHWA, 2003). A review of these traffic control methods and their effectiveness is beneficial in the evaluation of the proposed EFTCD.

Flaggers are employed in work zones often with various results. A study by Richards and Dudek (1986) indicated that flaggers were most efficient on two-lane, two-way rural highways and urban arterials where there was less competition for drivers' attentions. They also found that flaggers were well-suited for short-duration applications (less than one day) and for intermittent use at longduration work zones. Hill (2003) proved that flaggers were effective in reducing fatal work zone crashes. In fact, recent evaluations revealed that work zone flaggers could lower the odds of severe crash fatalities by $56 \%$ (Li and Bai, 2009). However, the study by Benekohal et al. (2005) indicated that there was a need for improving flagging for heavy-truck traffic. Their survey results showed that one third of the surveyed truck drivers believed that flaggers were hard to see, and half of them thought the flaggers' directions were confusing.

Traffic signs such as regulatory signs, warning signs, and guide signs are important in informing travelers of interrupted traffic conditions in work zones. A survey indicated that $50 \%$ of surveyed truck drivers wanted to see warning signs 3-5 miles in advance of the work zone (Benekohal et al., 2005). Garber and Woo (1990) found that static traffic signs could effectively reduce crashes in work zones on urban two-lane highways when used with flaggers. However, Li and Bai (2009) found that stop signs in work zones could triple the odds of crashes caused by following too closely. Channelizing devices, including cones, tubular markers, vertical panels, drums, barricades, and temporary raised islands, are also used to guide drivers safely through work zones. Results of a study showed that most channelizing devices successfully alerted and directed drivers; however, the devices were most effective only when arranged as a system (Pain et al., 1983).

Many studies have found that changeable message signs are often temporarily effective in reducing vehicle speeds in work zones. For example, a number of studies (Garber and Patel, 1994; Garber and Srinivasan, 1998; Brewer et al., 2006; Bai et al., 2010) revealed that a changeable message sign was more effective than traditional traffic control devices in reducing the number of speeding vehicles in work zones. Another evaluation showed that changeable message signs with radar effectively reduced vehicle speeds in the immediate vicinity of the sign (Dixon and Wang, 2002). However, vehicles often returned to their original speeds after passing the sign. In addition, Richards and Dudek (1986) commented that changeable message signs could result in only modest speed reductions (less than $16.1 \mathrm{kph}$ ) when used alone, and would lose their effectiveness when operated for long periods with the same messages.

Other traffic control devices that have proved effective in work zones are lighting devices, temporary traffic control signals, and modified optical speed bars. Some studies found that flashing warning lights, especially those of police vehicles, were one of the most effective methods in reducing speeds in work zones (Huebschman et al., 2003; Arnold, 2003). In addition, results of some work zone fatal crash analyses showed that certain TTC signals, such as STOP/GO signals, were very effective in reducing fatal crashes in work zones (Hill, 2003). Furthermore, Meyer (2004) conducted a study to evaluate the effectiveness of optical speed bars in reducing work zone speeds in Kansas. Results showed that the speed bars had both warning and perceptual effects, and were also successful in controlling speeds and reducing speed variations.

Rumble strips have also been found to be effective in the reduction of work zone speed. Two types of temporary transverse rumble strips were tested by Horowitz and Notbohm (2005). Test results showed that the rumble strips with a depth of $6.35 \mathrm{~mm}$ were as effective as cut-in-pavement rumble strips when vehicles traveled at $88.5 \mathrm{kph}$. The rumble strips with a depth of $19.05 \mathrm{~mm}$ were effective for vehicles traveling between 16.1 and $64.4 \mathrm{kph}$. Another evaluation of temporary rumble strips showed that properly designed strips could be easily installed and reinstalled (Meyer, 2006).

Despite the various studies of common traffic control methods and their effectiveness, the traffic control technique of utilizing a vehicle's emergency flashers as a warning device in the work zones has not been previously employed and evaluated. The proposed EFTCD may particularly benefit temporary one-lane, twoway highway work zones that require frequent movement during construction and maintenance operations.

\section{Experimental design}

After conducting a comprehensive literature review, the authors then performed field experiments to measure vehicle speed changes with and without the EFTCD in the upstream of three one-lane, two-way work zones in Kansas. The speed measurement devices, the experimental site selection, and the data collection procedure are described as follows.

\subsection{Speed measurement devices}

Evaluating the drivers' acceptance of the EFTCD required accurate measurement of vehicle speed changes in work zones, which was the indication of drivers' reactions. After a careful review of existing speed detection sensors, the Wavetronix SmartSensor HD 


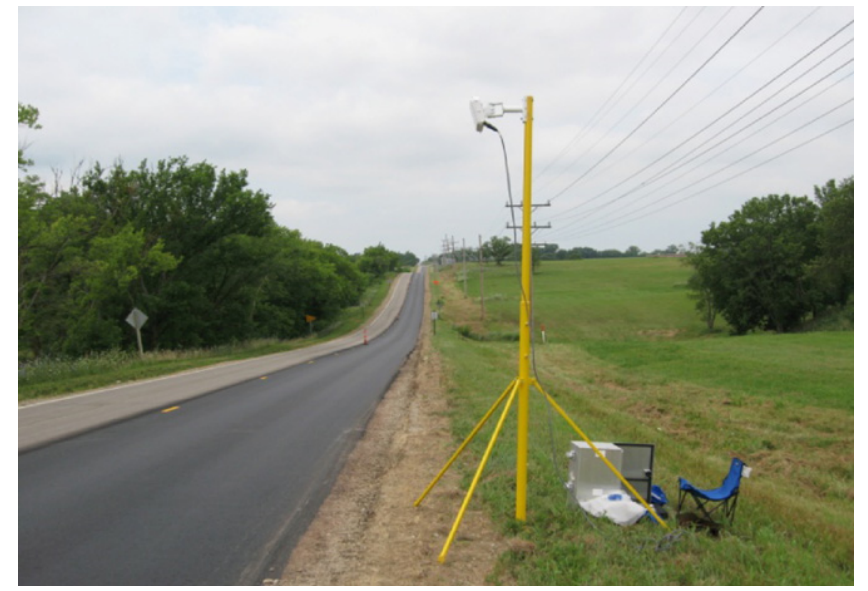

Fig. 1. A speed detector sensor installed at an experimental site.

Table 1

Experimental site information.

\begin{tabular}{lcr}
\hline Work zone location & Speed limit in kph $(\mathrm{mph})$ & \multicolumn{1}{c}{ AADT } \\
\hline US-36 & $104.6(65)$ & $1000-2500$ \\
K-192 & $88.5(55)$ & $750-1500$ \\
K-16 & $88.5(55)$ & $2500-5000$ \\
\hline
\end{tabular}

Note: AADT: Annual Average Daily Traffic.

Model 125, as shown in Fig. 1, was selected to measure the speeds of vehicles for this research project.

The SmartSensor HD was attached to a mounting post approximately $3.7 \mathrm{~m}$ above the ground and installed $2.4-3.7 \mathrm{~m}$ away from the travel lane. A 12.2-m cable connected the sensor with the central control panel located in the cabinet. This cable also delivered the speed measurements to the data ports in the control panel. Two $12-\mathrm{V}$ batteries were stored in the cabinet which could provide the required power to the sensor for eight consecutive days. To monitor real-time data collection and processing the information, a laptop computer was connected to the central control panel through an RS232 9-pin straight-through cable. In addition, the sensor was equipped with horizontal and vertical orientations as well as lane setup (direction, lane width, and lane location) for each installation in order to ensure proper function.

The speed comparison analyses had to differentiate between vehicle speeds with and without the EFTCD, thus requiring each speed datum to be clearly labeled when collected by the sensor. Furthermore, it was necessary to annotate the collected speeds with vehicle information, such as vehicle type and position in a queue, to ensure accurate speed analyses. As a result, a real-time human supervision was needed to properly identify and characterize the measured speed data. Vehicle types including passenger cars, minivans, pickups, campers or RVs, sport utility vehicles (SUVs), and all-terrain vehicles (ATVs) were classified as "lightduty vehicles." Vehicle types including single large trucks, truck and trailers, tractor-trailers, and buses were classified as "heavy trucks."

\subsection{Experimental site selection}

Three one-lane, two-way work zones in Kansas were selected for this study, see detail in Table 1. Other than availability, the three work zones were selected based on roadway type and work zone configurations as well as traffic characteristics. A flagger was used at each end of the work zones for traffic control and a pilot vehicle was employed to guide through traffic. Traffic characteristics, including traffic volume and typical traffic headways, were critical factors for the success of this study. If traffic volume of the study work zones was extremely low, such as only one vehicle at a time, a sufficient amount of data could not be collected for analysis. Therefore, traffic volume in the study work zones had to be moderate and the traffic headway between adjacent vehicles was about $229 \mathrm{~m}$ (750 ft).

\subsection{Data collection procedure}

Before defining the data collection procedure, there is a need to scale down the real world situation to the field experimental conditions. The proposed EFTCD is assembled using the emergency warning flashers of vehicles and is implemented by requiring drivers to turn on their emergency flashers when stopped at the entrance of a one-lane, two-way work zone in order to signal following vehicles of the upcoming work zone traffic conditions. Ideally, the drivers of all vehicles would consecutively illuminate their flashers until all of them safely reach the end of the work zone. Thus, drivers would receive additional warning of the traffic conditions from preceding vehicles, apart from the TTC devices already present in the work zones. However, under the field experimental conditions, it is impossible and unnecessary to measure the speed changes for every vehicle in a queue at a work zone. To be manageable, the field experiments only focused on the first two vehicles in the queue that stopped near the flagger at the entrance of a one-lane, two-way work zone. It is reasonable to assume that the effectiveness of the EFTCD on the first two vehicles could be replicated for other vehicles in the similar situation.

A successful experimental trial depended on the completion of the following chain of events: the compliance of the first driver when asked by a research assistant to turn on the vehicle's emergency flashers, sufficient headway between the first and the second vehicles, and the successful recording of the second vehicle speed. When any component of this action chain failed, the experiment trial also failed. To standardize the data collection procedure in the experiments, each time only first two vehicles were set up as the targets of the study.

After a number of field trials, the authors decided to install the SmartSensor HD approximately $152.4 \mathrm{~m}$ (500 ft) from the flagger in the work zone with the speed limit of $104.6 \mathrm{kph}$ (refer as $104.6 \mathrm{kph}$ work zone thereafter), and approximately $121.9 \mathrm{~m}$ ( $400 \mathrm{ft}$ ) from the flagger in the work zones with the speed limit of $88.5 \mathrm{kph}$ (refer as $88.5 \mathrm{kph}$ work zone thereafter). On-site observations showed that the first vehicle in a queue would typically stop at a distance less than $9.1 \mathrm{~m}$ from the flagger. The distance between the front bumper of the second vehicle and the flagger was typically less than $18.3 \mathrm{~m}$ if the leading vehicle was a light-duty vehicle. However, the distance was significantly larger (greater than $30.5 \mathrm{~m}$ ) if the leading vehicle was a heavy truck.

During the experiments, the speeds of the first vehicles in the queues were not collected since drivers of these vehicles did not have the EFTCD in front of them. Only the speeds of the second vehicles in the traffic queues were collected by the speed detector. After the speed of a passing vehicle was captured, the speed detector sent the speed datum to the laptop computer in real-time. The computer then displayed the speed on a graphic interface that simulated the passing vehicle. A research assistant examined each speed datum displayed on the computer and then recorded those that were correctly detected. The assistant discarded those that were evidently affected by factors other than the recognized work zone conditions. Interference factors included pedestrians, low-speed farm vehicles, or construction-related vehicles either operating at a very low speed or already slowing down for the upcoming work zone traffic conditions. It is important to note that a speed datum was considered a valid one only if the driver of the preceding vehicle (first vehicle driver) had turned on the emergency flashers well before the following vehicle driver (second vehicle driver) was able 
Table 2

Average speeds and speed reduction by work zones.

\begin{tabular}{|c|c|c|c|c|c|c|c|}
\hline \multirow[t]{2}{*}{ Work zone (kph) } & \multirow[t]{2}{*}{ Speed limit (kph) } & \multicolumn{2}{|l|}{ Sample size } & \multirow{2}{*}{$\begin{array}{l}\text { Average } \\
\text { without-warning } \\
\text { speed (kph) }\end{array}$} & \multirow{2}{*}{$\begin{array}{l}\text { Average } \\
\text { with-warning } \\
\text { speed (kph) }\end{array}$} & \multirow{2}{*}{$\begin{array}{l}\text { Speed } \\
\text { reduction }\end{array}$} & \multirow{2}{*}{$\begin{array}{l}\text { Reduction } \\
\%\end{array}$} \\
\hline & & Without warning & With warning & & & & \\
\hline US-36 & 104.6 & 40 & 46 & 65.0 & 57.6 & 7.4 & 11.4 \\
\hline K-192 & 88.5 & 21 & 18 & 52.9 & 53.4 & -0.5 & -0.9 \\
\hline K-16 & 88.5 & 57 & 46 & 58.6 & 52.8 & 5.8 & 9.9 \\
\hline
\end{tabular}

Note: A minus sign (-) means vehicle speed increase.

to distinguish them. As a result, the field experiments were time consuming because not every experimental trial successfully met pre-defined requirements.

There were two research assistants employed in the work zones to collect data. When the first vehicle was stopped by a flagger at the entrance of a work zone, one assistant required the driver to turn on the hazard warning flashers to alert the following vehicle of the upcoming work zone traffic conditions. Then, another assistant collected the second vehicle speed data using the speed detector sensor at another location.

\section{Speed data collection and analysis results}

A total of 228 speed data were collected, including 110 speeds with the EFTCD and 118 speeds without the EFTCD. Among the with-warning speed data, 64 were collected in the $88.5 \mathrm{kph}$ work zones and 46 were collected in the $104.6 \mathrm{kph}$ work zone. Among the without-warning speeds, 78 were collected in the $88.5 \mathrm{kph}$ work zones and 40 were collected in the $104.6 \mathrm{kph}$ work zone. The effectiveness of the EFTCD was first evaluated based on the comparison between with-warning speeds and without-warning speeds. If the vehicle speeds were reduced at the speed collection location after the warning device was utilized, it was inferred that vehicles decelerated more rapidly, started deceleration earlier, or both due to the recognition of the EFTCD.

Table 2 presents the average speeds observed in each experimental work zone and the speed reduction. As illustrated, the vehicle speeds collected at two of the three work zones decreased when the EFTCD was utilized. The reduction in average speed in the $104.6 \mathrm{kph}$ work zone was $7.4 \mathrm{kph}$, a noteworthy reduction of more than $11 \%$ compared to the average speed without the EFTCD. The speed reduction for one of the $88.5 \mathrm{kph}$ work zones was $5.8 \mathrm{kph}$ or $9.9 \%$. However, another $88.5 \mathrm{kph}$ work zone had a minor speed increase of $0.5 \mathrm{kph}$ or $0.9 \%$.

Among the three work zones, the average speed reduction in the $104.6 \mathrm{kph}$ work zone was considerably higher than the speed reduction in the two $88.5 \mathrm{kph}$ work zones. One possible explanation to this phenomenon is that the vehicles approaching the $104.6 \mathrm{kph}$ work zone might have traveled at higher initial speeds, a factor which may have allowed for a more dramatic speed reduction after being cautioned by the EFTCD. This larger speed reduction could be an indication of the greater effectiveness of the EFTCD in work zones with relatively high speed limits.

Data analyses showed a slight increase in average speed $(0.5 \mathrm{kph})$ after the implementation of the EFTCD in one of the $88.5 \mathrm{kph}$ work zones on K-192 highway. This observation is not consistent with the other two work zones where pronounced speed reductions were observed. Due to the construction progress, the authors collected only 39 vehicle speed data: 18 with-warning speeds and 21 without-warning speeds at this work zone. Therefore, the authors were unable to explain this inconsistency using statistical theories. However, results of drivers' surveys conducted at this work zone provided a possible explanation of this phenomenon, which was described in the next section.
Table 3

ANOVA tests for variance homogeneity at $88.5 \mathrm{kph}$ Work Zones.

\begin{tabular}{lll}
\hline ANOVA test & $p$-Value & Notation \\
\hline Levene's test & 0.565 & Cannot reject the null hypothesis \\
Brown and Forsythe's Test & 0.799 & Cannot reject the null hypothesis \\
Bartlett's test & 0.545 & Cannot reject the null hypothesis
\end{tabular}

Note: The null hypothesis in this test is that the variances of the with-warning speed data and without-warning speed data do not significantly differ.

The two-sample $t$-test was utilized to statistically verify the difference of means between the with-warning speeds and the without-warning speeds. In testing the difference between the means of the with-warning speed and the without-warning speed, the null hypothesis $\left(\mathrm{H}_{0}\right)$ and the alternative hypothesis $\left(\mathrm{H}_{1}\right)$ were defined as:

Ho. Mean 1 - Mean $2 \leq 0$

$\mathbf{H}_{\mathbf{1}}$. Mean $1-$ Mean $2>0$

where Mean 1 was the statistical mean of the without-warning speeds and Mean 2 was the mean of the with-warning speeds. Equivalently, the null hypothesis was interpreted to indicate that the mean of the without-warning speed data was no larger than that of the with-warning speed data. The alternative hypothesis, on the other hand, was interpreted to indicate that the mean of the without-warning speed data was larger than that of the withwarning speed data. A level of significance of 0.05 was used in the tests and a $p$-value no greater than 0.05 indicated that the null hypothesis could be confidently rejected.

For the $88.5 \mathrm{kph}$ work zone in the K-192 highway, it was clear that the null hypothesis could not be rejected; while the null hypothesis was rejected for the $88.5 \mathrm{kph}$ work zone in the $\mathrm{K}-16$ highway. Because K-16 and K-192 are identical highways based on the geometrics design and traffic flows and are located nearby areas, thus, the authors combined data from these two work zones and tested them together to determine if the null hypothesis could be rejected. Table 3 shows the results of three types of ANOVA tests for variance equality between the with-warning speed data and the without-warning speed data in these work zones. As shown in Table 3, all three ANOVA tests could not reject the null hypothesis, indicating that there was not enough evidence to determine whether the two variances were equal or not. In the next step, the authors calculated the $p$-values using the two-sample $t$-test under two conditions. One condition was assuming that variances were equal (using the Student's t-test) and another was assuming that variances were not equal (using the Smith-Satterthwaite test). Table 4 reveals the results of the $t$-test for the equality between the two means of the with-warning speed data and the without-

Table 4

Results of two-sample $t$-test for means of speeds at $88.5 \mathrm{kph}$ work zones.

\begin{tabular}{lllll}
\hline If variances were & $t$-Statistic & Degrees of freedom & $p$-Value & Reject $\mathrm{H}_{0}$ \\
\hline Equal & 2.45 & 140 & 0.008 & Yes \\
Not equal & 2.432 & 130.39 & 0.008 & Yes \\
\hline
\end{tabular}


Table 5

ANOVA tests for variance homogeneity at $104.6 \mathrm{kph}$ work zone.

\begin{tabular}{lll}
\hline ANOVA test & $p$-Value & Notation \\
\hline Levene's test & 0.046 & Reject the null hypothesis \\
Brown and Forsythe's test & 0.013 & Reject the null hypothesis \\
Bartlett's test & 0.037 & Reject the null hypothesis \\
\hline
\end{tabular}

Note: The null hypothesis in this test is that the variances of the with-warning speed data and without-warning speed data do not significantly differ.

warning speed data in two work zones. As shown in Table 4, both $p$-values were less than 0.05 under both conditions. Thus, based on the $p$-values the null hypothesis was rejected at both circumstances at the 0.05 level of significance using the combined data from two $88.5 \mathrm{kph}$ work zones.

Table 5 lists the three types of ANOVA test results regarding the difference between the variances of the two types of speed data collected in the $104.6 \mathrm{kph}$ work zone. The three ANOVA tests all indicated that the variances differed significantly at the 0.05 level of significance. Table 6 shows the results of the two-sample $t$-tests for the relationship between the means of the with-warning speed data and the without-warning speed data collected in the same work zone. As shown in Table 6 , the $t$-test had a $p$-value of 0.002 that indicated the null hypothesis was rejected at the 0.05 level of significance. The test statistically confirmed that the use of the EFTCD resulted in an overall speed reduction in the $104.6 \mathrm{kph}$ work zone.

\section{Drivers' acceptance survey}

Although it is clear that the EFTCD has potential to effectively reduce vehicle speeds in the work zones, the drivers' opinions of the newly proposed warning device remained uncertain. Without the cooperation of drivers, the EFTCD would be nonexistent. Therefore, the authors conducted additional research to determine the drivers' opinions on the utilization of the EFTCD in one-lane, two-way work zones using the survey method.

\subsection{Survey procedure}

Five survey questions with multiple-choice answers were developed and surveys were performed at the same work zones where field experiments were conducted. When the first vehicle in a queue was stopped by a flagger at the entrance of the work zone, the driver was required to turn on the vehicle's emergency flashers in order to alert the following vehicle of the upcoming work zone traffic conditions. Meantime, one research assistant (Assistant A) utilized the speed detection sensor to measure the speed of the second vehicle at a different location, and notified another research assistant (Assistant B) near the flagger (who would conduct the survey) whether the speed of the second vehicle was recorded successfully or not. If yes, then, Assistant B asked the driver of the second vehicle the survey questions because this driver had opportunities to recognize the EFTCD when approaching the work zones. Therefore, the drivers of the second vehicles were the best qualified people to answer the survey questions. Before conducting the survey, it was necessary to confirm that the speed of the second vehicle was captured by the detection sensor in order to guarantee that each driver survey had a corresponding vehicle speed. This allowed for

\section{Table 6}

Results of two-sample $t$-test for means of speeds at $104.6 \mathrm{kph}$ work zone.

\begin{tabular}{lllll}
\hline If variances are & $t$-Statistic & Degrees of freedom & $p$-Value & Reject $\mathrm{H}_{0}$ ? \\
\hline Equal & 2.95 & 84 & 0.002 & Yes \\
Not equal & 3.02 & 81.28 & 0.002 & Yes \\
\hline
\end{tabular}

Table 7

Response frequencies of the second survey question.

\begin{tabular}{lcc}
\hline Response & Frequency & Percent (\%) \\
\hline Emergency situation ahead & 33 & 36 \\
Dangerous situation ahead & 16 & 17 \\
Need to slow down & 60 & 65 \\
Don't know & 1 & 1 \\
Get confused & 0 & 0 \\
Other & 15 & 16 \\
\hline
\end{tabular}

the speed data and survey results to be analyzed together so that an in-depth understanding of the drivers' behaviors and their comprehensions of the EFTCD could be achieved. If a second vehicle speed was not recorded, the experiment trial was considered a failure and the survey would not be performed.

Drivers had to stop and wait approximately $10 \mathrm{~min}$ to pass through the work zones, which created a prime location to conduct surveys without causing further traffic delay that could lead to drivers' resistance in cooperating with the survey. Surveys at the entrance of the work zones resulted in more thoughtful and thorough feedback to the survey questions, as well as a higher percentage of successful surveys. Driver surveys were typically completed within $5 \mathrm{~min}$.

\subsection{Survey data analysis results}

The drivers' reactions to the EFTCD were a critical indication of the acceptance of the newly proposed EFTCD. A total of 110 drivers (second vehicle drivers) completed the five-question survey at the three experimental work zones, among them 41 females and 69 males. Only 14 of the surveyed vehicles were heavy trucks while the remaining were light-duty vehicles.

The analysis of the responses to the first question, Did you see the vehicle's flashers when you approached the work zone? revealed that the EFTCD successfully captured the attentions of $84 \%$ (92 out of 110 ) of the surveyed drivers. However, 16\% (18 out of 110 ) of the drivers did not see the EFTCD when they approached the work zones. Factors that may have contributed to the proportion of drivers who claimed to not see the EFTCD include sun glare, vehicles with indiscernible emergency flashers, and an unwillingness to participate. Therefore, the remaining analyses of the survey results are based on the 92 drivers who responded "Yes" to the first question.

Survey results for the second question as shown in Table 7 , How did you interpret the flashers? indicated that $65 \%$ of the drivers believed they needed to reduce their speeds after recognizing the previous vehicle's emergency flashers. More than half of these drivers interpreted the emergency flashers to indicate an emergency or dangerous traffic condition ahead. Among those drivers who chose "Other," 5 drivers believed the emergency flashers to indicate a broken-down vehicle, and 4 drivers believed the flashers to be a warning to drive with caution. None of the drivers considered themselves confused by the EFTCD in the work zones. A majority of the surveyed drivers selected multiple answers, and thus the frequency percentages in Table 7 do not equal 100\%.

Table 8 displays the response frequencies to the third question, What actions did you take after you saw the flashers? in which

Table 8

Response frequencies of the third survey question.

\begin{tabular}{lcc}
\hline Response & Frequency & Percent $(\%)$ \\
\hline Slow down & 32 & 35 \\
Slow down further & 19 & 21 \\
Look for more information & 14 & 15 \\
Do nothing & 37 & 40 \\
Other & 0 & 0 \\
\hline
\end{tabular}


Table 9

Response frequencies of the fourth survey question.

\begin{tabular}{llcl}
\hline Response & Effectiveness score & Frequency & Percent $(\%)$ \\
\hline Very much & 5 & 31 & 34 \\
Somewhat more & 4 & 27 & 29 \\
Some & 3 & 16 & 17 \\
Little & 2 & 9 & 10 \\
None & 1 & 9 & 10 \\
\hline
\end{tabular}

$56 \%(35 \%+21 \%)$ of the surveyed drivers slowed down or continued to slow down after recognizing the emergency flashers in the work zones. A small portion of the drivers (15\%) reported they looked for more information after seeing the previous vehicle's emergency flashers. It is worthy to note that a majority of the drivers (11 out of 14) who chose "look for more information" also selected either "slow down" or "slow down further." However, there were 37 drivers (40\%) who indicated they did nothing (maintaining the same driving pattern) after seeing the EFTCD in the work zones. Most of these drivers were from K-192 highway, and thus, explained why there was almost no difference of means between the with-warning speed data and the without-warning speed data in the work zone on K-192, as shown in Table 2. The "Do Nothing" phenomenon was difficult to explain from the engineering standpoint of view. One possible reason was that drivers might have confidence to handle the traffic situation, and thus, did not take any action. Another reason to explain why there was no speed reduction on highway K-192 was that the without-warning speeds were relatively low before implementing the EFTCD. In addition, other external factors influencing speeds at the highway K-192 might not be recognized and taken into consideration in the experiments. Additional field experiments are needed in the future to clearly explain this phenomenon.

When answering the fourth question, Did you think that the flashers brought you more attention to the work zone conditions? a majority of the drivers (80\%) considered the EFTCD effective (very much, somewhat more, and some) in alerting them of the work zone traffic conditions. Specifically, $34 \%$ of the drivers believed that the EFTCD was very effective, while $29 \%$ of the drivers indicated that the EFTCD had a relatively high effectiveness (effectiveness score of four). On the other hand, about $20 \%$ of the surveyed drivers rated the impact of the EFTCD as "Little" or "None." Table 9 summarizes the response frequencies of this question based on the analysis results.

The survey results of the fifth question, Do you prefer to use vehicles' flashers as a warning device in the work zones? were meaningful indications of the drivers' acceptance of the EFTCD. While only $12 \%$ of drivers did not support the use of the newly proposed traffic control device in the work zones, $82 \%$ recommended the utilization of the EFTCD, as shown in Table 10. In addition, $6 \%$ of drivers indicated no opinion on this question (Don't know).

\section{Conclusions and recommendations}

This paper presents the results of the evaluation of a newly proposed warning device, the Emergency Flasher Traffic Control Device (EFTCD), in one-lane, two-way highway work zones. The EFTCD was implemented by requiring drivers to turn on their emergency flashers when stopped at the entrance of a one-lane, two-way work zone with the flagger and the pilot car operation and was intended to

Table 10

Response frequencies of the fifth survey question.

\begin{tabular}{lcc}
\hline Response & Frequency & Percent (\%) \\
\hline Yes & 75 & 82 \\
No & 11 & 12 \\
Don't know & 6 & 6 \\
\hline
\end{tabular}

provide additional warning of traffic conditions with the objective of preventing the rear-end crashes attributable to inattentive driving in the work zones. Evaluations of drivers' acceptance of EFTCD including vehicle mean speed changes and drivers' surveys were conducted in two $88.5 \mathrm{kph}$ work zones and one $104.6 \mathrm{kph}$ work zone in Kansas.

When the EFTCD was utilized in the $104.6 \mathrm{kph}$ work zone, the average vehicle speeds were reduced by more than $11 \%$, or $7.4 \mathrm{kph}$. When the EFTCD was employed in the $88.5 \mathrm{kph}$ work zones, one work zone on the K-16 highway showed $9.9 \%$ or $5.8 \mathrm{kph}$ vehicle speed reduction and another work zone on the K-192 highway had slight speed increase at $0.9 \%$ or $0.5 \mathrm{kph}$. Survey results indicated that most of the drivers did nothing (maintaining the same driving pattern) after seeing the EFTCD in the K-192 highway. That explained why there was almost no difference of means between the with-warning speed data and the without-warning speed data in the work zone on K-192. The "Do Nothing" phenomenon was difficult to explain from the engineering standpoint of view. One possible reason was that drivers might have confidence to handle the traffic situation, and thus, did not take any action. Results of two-sample $t$-test showed that the use of the EFTCD resulted in the mean speed reductions in three work zones. Therefore, the outcomes of field experiments confirmed that the EFTCD had potential to effectively reduce vehicle speeds in the upstream of one-lane, two-way highway work zones. A slow speed is more likely to reduce the severity of a crash in work zones, thus, provide a safer environment for the drivers and construction workers.

In addition to the field experiments, surveys were performed at the same work zones to determine the drivers' opinions of the EFTCD. Results of the 92 completed surveys supported the effectiveness of the EFTCD and acknowledged its usefulness in the one-lane, two-way highway work zones. Analyses of the survey results indicated that a majority of the drivers were able to recognize the EFTCD in the work zones. More than half of the motorists considered the emergency flashers an indication of either a dangerous or emergency situation ahead; $60 \%$ of the drivers thought the traffic device signified a need for speed reduction. In addition, approximately $56 \%$ of the drivers slowed down or continued to slow down upon seeing the emergency flashers. When asked about the effectiveness of the EFTCD in capturing the attention of drivers, more than $80 \%$ of the drivers expressed positive feedback. In particular, one-third of the drivers considered the EFTCD a very effective warning device in alerting drivers of the complicated traffic conditions in the work zones. Consequently, a majority of the drivers ( $82 \%$ ) recommended the implementation of the new traffic control device in the work zones. Based on the speed and survey analysis results, authors were able to conclude that the EFTCD was accepted by the majority of drivers as an effective traffic control device in one-lane, two-way work zones.

Based on the results of the evaluation, the authors recommend the government agencies to implement the EFTCD in one-lane, twoway highway work zones. Furthermore, the authors recommend extending this research project in several ways. First, additional field experiments are needed, particularly, in the $88.5 \mathrm{kph}$ work zones. Second, the implementation procedure needs to be developed. In the field experiments, drivers were asked by a research assistant to turn on the vehicle emergency flashes at the entrance of the work zones. To implement the EFTCD in the real world, two advanced warning signs with the message, "Turn on Vehicle Emergency Flashers When Stopped," should be installed to instruct drivers to turn on their emergency flashers. Third, education programs are required to train the general public about the function and purpose of the EFTCD. Fourth, the long-term effectiveness of the proposed EFTCD is not clear at present time due to the short duration of this research project. Drivers had not seen this type of warning device before this research project so their reactions 
might be cautious. It is a common consensus that the effectiveness of a newly proposed traffic control device may diminish over time, and it is possible that drivers' speed reductions in response to the EFTCD might decrease over time. Thus, further research is necessary to determine the long-term effectiveness of the EFTCD. Fifth, due to the scope of this research project, the authors didn't spend time to find out exact reasons why some drivers did not see the EFTCD in the work zones. This could be a topic for future research if additional resource is available. Finally, vehicle crash data in the one-lane, two-way work zones before and after implementing the EFTCD need to be compared in the future to determine the effectiveness of EFTCD.

\section{Acknowledgements}

Authors would like to thank Mr. Anthony Alrobaire and Ms. Dawn Hueske from the Kansas Department of Transportation (KDOT) for their valuable help and advice during the course of this study. Cooperation and assistance from other KDOT staff during the process of field experiments are also greatly appreciated. The financial support that contributed to the success of this research was fully provided by KDOT. Authors would also like to thank University of Kansas undergraduate students Brandon T. Harvey and Megan Mills for their assistance.

\section{References}

Arnold, E.D., 2003. Use of Police in Work Zones on Highways in Virginia. Final Report VTRC 04-R9. Virginia Transportation Research Council, Charlottesville, VA.

Bai, Y., Finger, K., Li, Y., 2010. Analyzing motorists' responses to temporary signage in highway work zones. Safety Science 48 (2), 215-221, Elsevier.

Bai, Y., Li, Y., 2006. Determining Major Causes of Highway Work Zone Accidents in Kansas, Final Report. Kansas Department of Transportation Research Project KAN37040, June 2006, 168 pp.

Bai, Y., Li, Y., 2007. Determining Major Causes of Highway Work Zone Accidents in Kansas-Phase II, Final Report. Kansas Department of Transportation Research Project KAN41000, October 2007, 134 pp.
Benekohal, R.F., Shim, E., Resende, P.T.V., 2005. Truck drivers' concerns in work zones: travel characteristics and accident experiences. In: Transportation Research Record 1509. Transportation Research Board, Washington, DC, pp. 55-64.

Brewer, M.A., Pesti, G., Schneider IV, W., 2006. Improving compliance with work zone speed limits: effectiveness of selected device. In: Transportation Research Record 1948. Transportation Research Board, Washington, DC, pp. 67 76.

Dixon, K.K., Wang, C., 2002. Development of Speed Reduction Strategies for Highway Work Zones. Research Report. Georgia Transportation Institute, Georgia Institute of Technology, Atlanta, GA.

FHWA, 2003. Temporary traffic control. In: Manual on Uniform Traffic Control Devices for Streets and Highways. Federal Highway Administration (FHWA), chapter 6.

Garber, N.J., Patel, S.T., 1994. Effectiveness of Changeable Message Signs in Controlling Vehicles Speeds in Work Zones Report No. VTRC 95-R4. Virginia Transportation Research Council, Charlottesville, VA.

Garber, N.J., Srinivasan, S., 1998. Effectiveness of changeable message signs in work zones: phase II. In: Report No. VTRC 98-R 10. Virginia Transportation Research Council, Charlottesville, VA.

Garber, N.J., Woo, T.H., 1990. Accident characteristics at construction and maintenance zones in urban areas. In: Report No. VTRC 90-R12. Virginia Transportation Research Council.

Hill, R.W., 2003. Statistical Analysis of Fatal Traffic Accident Data. Master's Thesis. Texas Tech University.

Horowitz, A.J., Notbohm, T., 2005. Testing Temporary Work Zone Rumble Strips. Research Report. University of Wisconsin at Milwaukee, Milwaukee WI.

Huebschman, C.R., Garcia, C., Bullock, D.M., Abraham, D.M., 2003. Construction work zone safety. Report No. FHWA/IN/JTRP-2002/34. In: Joint Transportation Research Program. Purdue University, West Lafayette IN.

Li, Y., Bai, Y., 2009. Effectiveness of temporary traffic control measures in highway work zones. Safety Science 47 (3), 453-458, Elsevier.

Meyer, E., 2004. Evaluation of data from test application of optical speed bars to highway work zones. In: Final Report No. K-TRAN: KU-00-4. Kansas Department of Transportation.

Meyer, E., 2006. Evaluation of Portable Rumble Strips-ATM. Research Report. Meyer ITS, Lawrence, KS.

Pain, R.F., McGee, H.W., Knapp, B.G., 1983. Evaluation of traffic controls for highway work zones. In: NCHRP Report 236. Transportation Research Board, Washington, DC.

Richards, S.H., Dudek, C.L., 1986. Implementation of work-zone speed control measures. In: Transportation Research Record 1086. Transportation Research Board, Washington, DC, pp. 36-42. 